\title{
A study on the relationship between Narcissism and Self Efficacy
}

\author{
Vinanthi K.Hegde ${ }^{1}$, Vidyadayini Shetty ${ }^{2}$ \\ ${ }^{1}$ Student, Department of Psychology, Nagindas Khandwala College, Mumbai. \\ ${ }^{2}$ Associate Professor, Department of Psychology, Nagindas Khandwala College, Mumbai \\ Corresponding Author: Vidyadayini Shetty \\ E-mail: vidhi33@gmail.com
}

\begin{abstract}
Background: Narcissism is characterized by an unrealistic, inflated sense of self-importance and a lack of sensitivity to the needs of other people. Self-efficacy reflects confidence in the ability to exert control over one's own motivation, behavior, and social environment. The present study aims to find out whether being narcissists or having high narcissistic traits can lead to any positive benefits to individuals, in other words, whether their self-efficacy increases.

Methodology: For the present investigation a sample of 60 were selected and is segregated into 3 age groups - Adolescents (10M 10F), Young Adulthood (10M 10F), Middle Adulthood (10M 10F). Two scales were administered on these participants - NPI- 16 Subclinical Narcissism Scale and General Self-efficacy Scale. Descriptive, Correlation Analysis, t-test and ANOVA was done on the data using Mega Stats.

Results: The mean score of narcissism was 3.85, and mean score of self-efficacy was 31.20 , indicating moderate levels of narcissism and self-efficacy. The obtained $r$ value (.328) was greater than the critical value (.254) pointing to a significant positive relationship between scores of narcissism and self-efficacy. The mean scores of narcissism and self-efficacy of female respondents was lower than that of male respondents. However, the differences were not statistically significant. The $\mathrm{F}$ value indicate that there was no significant difference in the scores of narcissism and self-efficacy of people belonging to different age groups.

Conclusion: The results indicate that there is a significant positive, but weak relationship between narcissism and self-efficacy. Gender and age did not have any influence on narcissism and self-efficacy.
\end{abstract}

Keywords: narcissism, self- efficacy, gender, age

(Paper received $-10^{\text {th }}$ March 2020, Peer review completed $-25^{\text {th }}$ March 2020)

(Accepted $-27^{\text {th }}$ March 2020)

\section{INTRODUCTION}

One of the main reasons to conduct this study was that we notice in this era, people are so much into themselves, don't care about others, and are so self-obsessed. It is not bad to self-love or be self-obsessed but it can be harmful if it exceeds a particular border, and we call this term as Narcissism. The authors were interested in finding out whether being narcissists or having high narcissistic traits can lead to any positive benefits to individuals, in other words, whether their self-efficacy increases. Narcissism is characterized by an unrealistic, inflated sense of self-importance and a lack of sensitivity to the needs of other people [1]. They see themselves as exceptional and have a strong sense of entitlement. Because they see themselves as exceptional, they may set their personal standards as unrealistically high. Conversely, they may regard themselves as entitled to whatever they want and therefore set their personal standards far too low. Their impairments in goal setting also includes a constant attempt to gain approval from other people. Although narcissists can be difficult and at times insufferable, they can also make effective leaders and performers. Moreover, because virtually all of us share at least a few narcissistic traits, we may be able to learn something 
about ourselves from understanding them [2]. Self-efficacy reflects confidence in the ability to exert control over one's own motivation, behavior, and social environment. These cognitive self-evaluations influence all manner of human experience, including the goals for which people strive, the amount of energy expended toward goal achievement, and likelihood of attaining particular levels of behavioral performance. Unlike traditional psychological constructs, self-efficacy beliefs are hypothesized to vary depending on the domain of functioning and circumstances surrounding the occurrence of behavior [3].

Since narcissism is all about excessive self-love and belief that one is unique, then they should be very particular about completing their own tasks with a lot of confidence and perfection, as the authors feel that if they reach their goals, it will help them to validate their self-belief. The purpose of this research was to investigate the relationship between narcissism and self-efficacy.

Hypotheses for the current study were:

- There will be no significant relationship between the scores of narcissism and self- efficacy.

- There will be no significant gender differences in the scores of narcissism and self-efficacy.

- There will be no significant difference in the scores of narcissism and self-efficacy among different age groups.

\section{METHODOLOGY}

For the present investigation a sample of 60 were selected and is segregated into 3 age groups - Adolescents (12-20 years); Young adulthood (21- 40 years); and Middle adulthood (41- 60 years). Each age group consisted of 10 males and 10 females. And all the participant are residents to Mumbai City and well-versed in English language. The data was collected using the snow ball technique. Google forms of the scales were prepared and were sent to the individuals, who then were asked to forward it. The respondents were required to fill the consent form. 86 respondents filled the questionnaires, however, responses of 60 participants were selected as they fulfilled the criteria of participation.

The following scales were used to measure narcissism and self-efficacy:

- NPI- 16 Subclinical Narcissism: The test has 16 pairs of statements and the participants has to select the sentences which comes closest to describing their feelings and belief about themselves. Score ranges from 0 to 16 , with higher scores on the scale indicate high level of narcissism trait. $a=$ 0.72 ; mean inter-item correlation $=0.13$; loadings on the unrotated factor ranged from 0.13 to 0.66 with the first factor capturing 19.99 percent of variance; correlated with the NPI-40 at $r=0.9$ ( $p<$ .001) [4].

- General Self-Efficacy Scale: The 10 items scale created to assess a general sense of perceived selfefficacy has 4 options and each question is to be answered by putting a tick mark on any of the 1 option out of 4 . The total score is calculated by finding the sums of all the items. For the GSE, the total score ranges from 10 to 40 , with a higher score indicating more self-efficacy. Internal reliability for GSE = Cronbach's alphas between 0.76 and 0.9 [5].

\section{STATISTICAL ANALYSIS}

Descriptive method (mean and standard deviation) was calculated. Correlational co-efficient method was used to find the significant relationship between narcissism and self-efficacy. One way ANOVA was used to collect data on significant difference in narcissism and self-efficacy among the three age groups. t-test was used to find gender differences in narcissism and self-efficacy. Mega Stats was used to all calculate all of these statistical tests.

\section{RESULTS \& DISCUSSION}

The mean score of narcissism was 3.85, and mean score of self-efficacy was 31.20 , indicating moderate levels of narcissism and self-efficacy. The first hypothesis was to investigate whether there is any relationship between narcissism and self-efficacy. Here the obtained $r$ value $(0.328)$ is more than the critical value $(0.254)$, so the findings were not consistent with the null hypothesis. The results indicate that there is a significant 
positive, low relationship between scores of narcissism and self-efficacy. In other words, the results indicate that as scores on narcissism increases, there is a proportional increase in the scores on self-efficacy of the person. Literature on narcissism and self-efficacy indicate mixed findings. The present results are consistent with a study conducted to explore the role of narcissism in entrepreneurship which indicated that student entrepreneurs are more narcissist than that of students who are non-entrepreneurs and narcissism was positively associated with high scores on general self-efficacy, LOC and risk propensity [6]. However, another study point to the fact that when narcissism was high, performance had no relationship with subsequent self-efficacy; narcissism has a negative effects on entrepreneurial self-efficacy [7-8].

Table 1: Correlation between Narcissism and Self-efficacy

\begin{tabular}{|l|l|l|}
\hline & Narcissism & Self-efficacy \\
\hline Narcissism & 1.000 & \\
\hline Self-efficacy & $.328^{*}$ & 1.000 \\
\hline${ }^{*} \mathrm{p}<0.05$
\end{tabular}

Table 2: Mean and SD of Narcissism and Self-efficacy among males and females

\begin{tabular}{|l|rr|rr|}
\hline & \multicolumn{2}{|c|}{ Narcissism } & \multicolumn{2}{c|}{ Self-efficacy } \\
\hline & Mean & SD & Mean & SD \\
\hline Males & 4.17 & 2.29 & 32.13 & 4.16 \\
\hline Females & 3.53 & 2.43 & 30.27 & 4.71 \\
\hline t-value & \multicolumn{2}{|c|}{-1.04 NS } & \multicolumn{2}{c|}{-1.63 NS } \\
\hline p-value & \multicolumn{3}{|c|}{0.3034} & 0.1092 \\
\hline
\end{tabular}

Males and females indicate moderate levels of narcissism and self-efficacy. The mean scores of narcissism and self-efficacy of female respondents was lower than that of male respondents. However, the $t$ values of both variables indicate no statistically significant difference in narcissism and self-efficacy among males and females. Despite the widely held belief that men are more narcissistic than women, there has been no systematic review to establish the magnitude, variability across measures and settings, and stability over time of this gender difference. The findings of the present study were not consistent with past study which found men tend to be at a high risk to develop the traits of narcissism [9].

Table 3: Mean, SD and F value of Narcissism and Self-efficacy of different age groups

\begin{tabular}{|l|cc|cc|}
\hline & \multicolumn{2}{|c|}{ Narcissism } & \multicolumn{2}{c|}{ Self-efficacy } \\
\hline & Mean & SD & Mean & SD \\
\hline Adolescent & 3.8 & 2.31 & 29.7 & 5.02 \\
\hline Young Adulthood & 4.7 & 2.52 & 31.5 & 4.27 \\
\hline Middle Adulthood & 3.1 & 2.06 & 32.5 & 3.90 \\
\hline F value & \multicolumn{2}{|c|}{2.57 NS } & \multicolumn{2}{c|}{0.13 NS } \\
\hline p value & \multicolumn{2}{|c|}{0.0851} & \multicolumn{2}{c|}{} \\
\hline
\end{tabular}

The third hypothesis investigated the influence of age on the scores of narcissism and self-efficacy. The mean scores on narcissism of people belonging to young adulthood was higher than mean scores of adolescent and middle adulthood groups, which means that young adults exhibit high narcissistic traits when compared to other age groups. The mean scores of self-efficacy indicate that individuals who are in their middle adulthood 
are high on self-efficacy followed by individuals on their young adulthood and least of adolescents. However, the $\mathrm{F}$ value indicate that age did not have any influence on narcissism and self-efficacy. The results did not follow a study that investigated the relationship between age, socioeconomic status, and self-efficacy, which confirm that individuals belonging to age group of 45 years to 65 years score more on self-efficacy [10]. To summarize, narcissism is considered as one of the negative traits, nevertheless, with training people with high scores on narcissism could be helped to develop their self-efficacy. That is individuals having high scores on narcissism can achieve their goals, which could help them to satisfy their need for self-admiration and special treatment. This in turn will help to increase their productivity and develop leadership skills. However, more research should be conducted to validate these assumptions.

\section{CONCLUSION}

The results indicate that there is a significant positive, but weak relationship between narcissism and selfefficacy. There is no difference between the scores of narcissism and self-efficacy of males and females. Similarly, age did not have any influence on narcissism and self-efficacy.

\section{REFERENCES}

1. Whitebourne SK, Halgin RP. Abnormal Psychology: Clinical perspective on Psychological disorders. $7^{\text {th }}$ edition DSM 5 update, McGraw Hill Education (India) Edition, 2015.

2. Carey MP, Forsyth AD. Teaching Tip Sheet: Self-Efficacy. Retrieved from https://www.apa.org/pi/aids/resources/education/self-efficacy.

3. Lilienfeld SO, Arkowitz H. A dose of Narcissism can useful - All about Me. Scientifc American Mind 2013;23(6):64-8.

4. Ames DR, Rose P, Anderson CP. NPI- 16 as a short measure of narcissism. J Res Personality 2013;40:440 50 .

5. Luszczynska A, Scholz U, Schwarzer R. The general self-efficacy scale: multicultural validation studies. J Psychology 2005;139(5):439-57.

6. Mathieu C, St-Jean É. Entrepreneurial personality: The role of narcissism. Personal Individ Diff 2013;55(5):527-31.

7. Beattie S, Dempsey C, Roberts R, Woodman T, Cooke A. The moderating role of narcissism on the reciprocal relationship between self-efficacy and performance. Sport Exer Perform Psychol 2017;6(2):199-214.

8. Wu W, Wang $\mathrm{H}$, Zheng $\mathrm{C}$, Wu J. Effect of Narcissism, Psychopathy, and Machiavellianism on Entrepreneurial Intention-The Mediating of Entrepreneurial Self-Efficacy. Front Psychol 2019;10:360.

9. Grijalva E, Newman DA, Tay L, Donnellan MB, Harms PD, Robins RW, Yan T. Gender differences in narcissism: A meta-analytic review. Psychol Bull 2015;141(2):261-310.

10. Clark DO. Age, Socioeconomic Status, and Exercise Self-Efficacy. Gerontologist 1996;36(2):157-64.

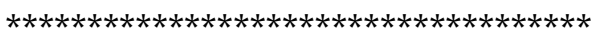

$$
\begin{gathered}
\text { Acknowledgements - Nil } \\
\text { Conflict of Interest - Nil } \\
\text { Funding - Nil }
\end{gathered}
$$

